\title{
Efficient Preparation and Performance Characterization of the HMX/F 2602 Microspheres by One-Step Granulation Process
}

\author{
Conghua Hou, ${ }^{1}$ Xinlei Jia, ${ }^{1}$ Jingyu Wang, ${ }^{1}$ Yingxin Tan, ${ }^{1}$ Yuanping Zhang, ${ }^{1}$ and Chao Li ${ }^{2}$ \\ ${ }^{1}$ School of Chemical and Environmental Engineering, Shanxi Engineering Technology Research Center for Ultrafine Powder, \\ North University of China, Taiyuan, Shanxi 030051, China \\ ${ }^{2}$ Department of Resources and Environment, Binzhou University, Binzhou, Shandong 256600, China
}

Correspondence should be addressed to Xinlei Jia; 1004024260@qq.com

Received 4 August 2017; Revised 2 November 2017; Accepted 27 November 2017; Published 18 December 2017

Academic Editor: Domenico Acierno

Copyright (C) 2017 Conghua Hou et al. This is an open access article distributed under the Creative Commons Attribution License, which permits unrestricted use, distribution, and reproduction in any medium, provided the original work is properly cited.

\begin{abstract}
A new one-step granulation process for preparing high melting explosive- (HMX-) based PBX was developed. HMX/F 2602 microspheres were successfully prepared by using HMX and $\mathrm{F}_{2602}$ as the main explosive and binder, respectively. The particle morphology, particle size, crystal structure, thermal stability, and impact sensitivity of the as-prepared HMX/ $\mathrm{F}_{2602}$ microspheres were characterized by scanning electron microscopy (SEM), X-ray diffraction (XRD), laser particle size analyzer, differential scanning calorimetry (DSC), and impact sensitivity test, respectively. The SEM analysis indicated successful coating of $\mathrm{F}_{2602}$ on the surface of HMX, and the resulting particles are ellipsoidal or spherical with a median particle size of $940 \mathrm{~nm}$; the XRD analysis did not show any change in the crystal structure after the coating and still has $\beta$-HNX crystal structure; according to the DSC analysis, $\mathrm{HMX} / \mathrm{F}_{2602}$ prepared by the new method has better thermal stability compared to that prepared by the water suspension process. The impact sensitivity of $\mathrm{HMX} / \mathrm{F}_{2602}$ prepared by this one-step granulation process decreased, and its characteristic height $\mathrm{H}_{50}$ increased from 37.62 to $40.13 \mathrm{~cm}$, thus significantly improving the safety performance. More importantly, this method does not need the freeze-drying process after recrystallization, thus increasing the efficiency by 2 to 3 times.
\end{abstract}

\section{Introduction}

HMX is the elemental explosive produced with the highest detonation velocity and the best comprehensive properties [1]. Its good thermal stability and the high melting point not only can make it be used as ammunition alone or mixed with TNT for high power missile warheads and rockets but also can replace ammonium perchlorate as the propellant oxidizer [2]. But it has high impact sensitivity and it is easy to blast. So there are a lot of potential safety problems in the process of production, storage, and transportation. All of these defects restrict the application range of HMX.

Therefore, in order to get more applications, HMX must be taken pretreatment to decrease sensitivity [3]. At present, coating is the most convenient way to improve the comprehensive performance of the explosive. These HMX-based PBX explosives are multicomponent mixed explosives, which are prepared by taking HMX as the main ingredient and adding a variety of additives to improve the performance.
Currently, fluorine polymer is frequently used as the binder of PBX [4-6], given its specific advantages, such as higher burning rates, lower impact sensitivity, and better thermal stability. There are many preparation methods for mixed explosives. The commonly used methods are the following: solution-water suspension method [7], solution suspension method [8], water suspension distillation coating method [9, 10], extrusion granulation method [11], and supercritical fluid coating method [12]. In 2015, Na and Xu [13] studied the coating modification of ACM on HMX through water suspension coating. The prepared particles had larger coating defects. The distribution of particles was uneven and the particle size was not uniform. There were a lot of agglomerates and the coated surface was rough and easy to break up. In 2016, Ji et al. $[9,10]$ prepared the $\mathrm{HMX} / \mathrm{F}_{2602}$ core-shell composite microspheres by using spray drying technique. The particle size distribution of the prepared particles was uniform and the morphology was regular. But the coating layer of $\mathrm{HMX} / \mathrm{F}_{2602}$ microspheres prepared by this method was 
relatively thin and its effect of reducing the sensitivity is not obvious.

The mechanism of one-step granulation method is similar to that of spray drying method. It is nitration explosive coverage method integrating the technology of refinement and coating, but there is a big difference between the two methods. We use the homemade nozzle to make high-temperature steam environment in the five-necked flask, and the whole experiment process of coating is carried out under the vacuum state. This increases the flow speed of gas molecules and fog water vapor in the reaction container. Active gases and water molecules are in complete contact with the organic solvent that dissolves the binder and is discharged from the reaction vessel, driven by high-speed moving gases and water molecules and then discharged from the reaction vessel, driven by high-speed moving gases and water molecules. This equipment is simple and easy to operate, the safe performance is obviously improved, and the test cost is low. On the basis of the refinement and coating mechanism of the fire explosive, through the self-made nozzle and pressure device, and on the basis of ensuring that the crystal structure of explosives does not change, combining the refinement and coating of explosives can solve some of the problems in existing HMX coating; for example, the coated particle size is larger, the particles are distributed unevenly, and the effect of reducing the sensitivity is poor. More importantly, we effectively solve the problems of thin coating layer and the bad effect of reducing the sensitivity when using spray drying method. Our method provides certain reference value for the development of high-energy low-sensitive explosives.

This paper introduces a new method to prepare the $\mathrm{HMX} / \mathrm{F}_{2602}$ microspheres. Second, the microstructure and performance of the coated HMX are characterized. Besides, the $\mathrm{HMX} / \mathrm{F}_{2602}$ shows enhanced thermal stability and reduced impact sensitivity. More importantly, the entire coating process eliminates the process of HMX refining and drying, and the work efficiency increased by 2 to 3 times.

\section{Experiment Parts}

2.1. Materials. HMX was provided by Gansu Yinguang Chemical Industry Group Co., Ltd.; dimethyl sulfoxide came from Liaoyang Chemical Co., Ltd.; ethyl acetate was provided by Nanjing Chemical Reagent Co., Ltd.; fluorine rubber $\left(\mathrm{F}_{2602}\right)$ came from Wu Chen Light Chemical Industry Research Institute; pure water was provided by pure water supply of Taiyuan Iron and Steel Co., Ltd.; Samtec ethanol was provided by Tianjin Chemical Reagent Co., Ltd.

\subsection{Preparation of $H M X / F_{2602}$}

2.2.1. Preparation of $H M X / F_{2602}$ by the Method of One-Step Granulation Process. The preparation of $\mathrm{HMX} / \mathrm{F}_{2602}$ by the method of one-step granulation process was divided into three steps in detail. Firstly, pour the HMX solution, the binder $\left(\mathrm{F}_{2602}\right)$, and the deionized water at $90^{\circ} \mathrm{C}$ into the homemade spray containers 7, 8, and 9 for use, respectively, according to $\mathrm{M}_{\mathrm{HMX}}: \mathrm{M}_{\mathrm{F} 2602}:$ water $=97: 3: 1000$; then pour

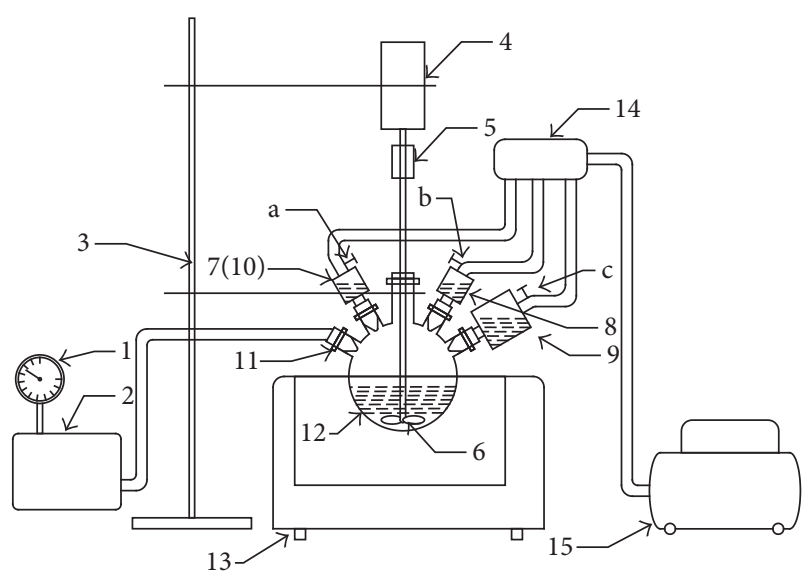

FIGURE 1: Experimental apparatus of the one-step granulation process.

the distilled water into a homemade five-necked flask according to $\mathrm{M}_{\mathrm{HMX}}: \mathrm{M}_{\text {distilled water }}=1: 40$; meanwhile, control the stirring speed $R=400 \mathrm{rad} / \mathrm{min}$. Secondly, open the selfmade nozzles a and c connected to the spray containers 7 and 9 at an ultrasonic frequency of $50 \mathrm{KHZ}$ and an injection pressure of $0.6 \mathrm{MPa}$. After forming a high-temperature water vapor environment in the five-necked flask, open the nozzle $\mathrm{b}$ connected to the spray container 8. At this time, the ethyl acetate dissolving the binder $\left(\mathrm{F}_{2602}\right)$ was in complete contact with the high-temperature water vapor and then discharged from the reaction vessel under the action of the vacuum pump. The precipitated fog binder fully contacted with the recrystallized HMX particles and then completed the coating process. Finally, with the solution standing, suction, and drying, then get the high quality solid $\mathrm{HMX} / \mathrm{F}_{2602}$ particles. Experimental apparatus is shown in Figure 1: 1, pressure gauge; 2 , vacuum pump; 3 , stirrer device; 4 , S312 digital stirring hotplate; 5 , electric machine; 6 , mixture solution; 7-10, container; 11, connecting device; 12, five-necked flask; 13, ultrasonic machine; 14, dispenser; 15 , air oil-less compressor; a-c, shower nozzle.

2.2.2. Preparation of $H M X / F_{2602}$ by the Method of Water Suspension Process. The process of the preparation of HMX/ $\mathrm{F}_{2602}$ by the method of water suspension process was as follows: firstly, add $3 \mathrm{~g}$ thinning HMX into $120 \mathrm{~mL}$ distilled water, and then make HMX-water suspension solution under stirring; secondly, weigh a certain amount of $\mathrm{F}_{2602}$ and dissolve it in ethyl acetate, and prepare them into a solution with certain concentration; at last, the prepared $\mathrm{F}_{2602}$-ethyl acetate solution was added dropwise into the HMX-water suspension solution at a uniform speed; stir for $2 \mathrm{~h}$ at constant temperature. After vacuuming, sieving, filtrating, washing, freezedrying, and other processes, $\mathrm{HMX} / \mathrm{F}_{2602}$ were obtained.

For the convenience of comparison, we mark HMX/ $\mathrm{F}_{2602}$ prepared by water suspension coating as $\mathrm{HMX} / \mathrm{F}_{2602}-0$ in this paper.

2.3. Characterization. Field emission scanning electron microscope (FESEM, S4700 Hitachi, Ltd., Japan) was used 


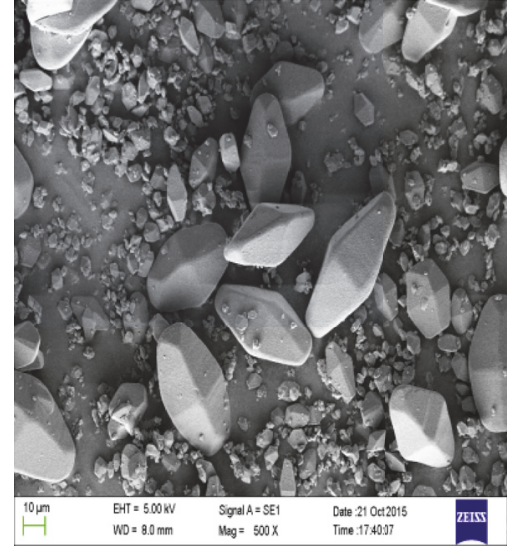

(a) Refined HMX

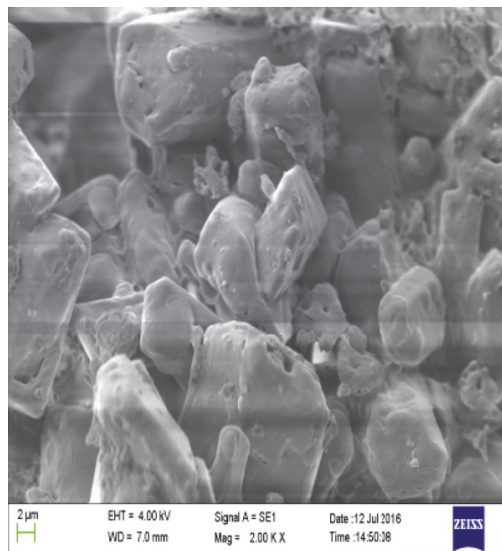

(b) $\mathrm{HMX} / \mathrm{F}_{2602^{-0}}$

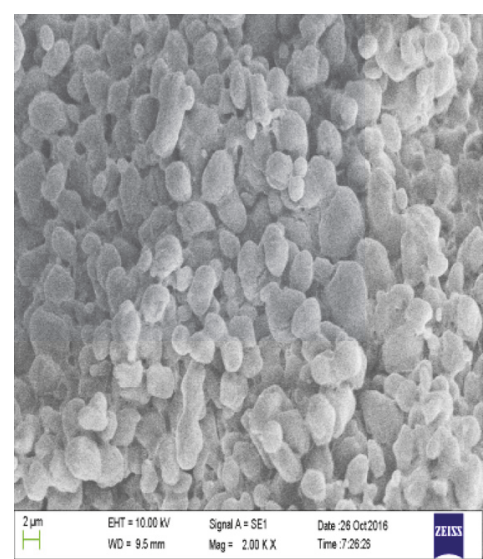

(c) $\mathrm{HMX} / \mathrm{F}_{2602}$

FIGURE 2: SEM images of different HMX samples.

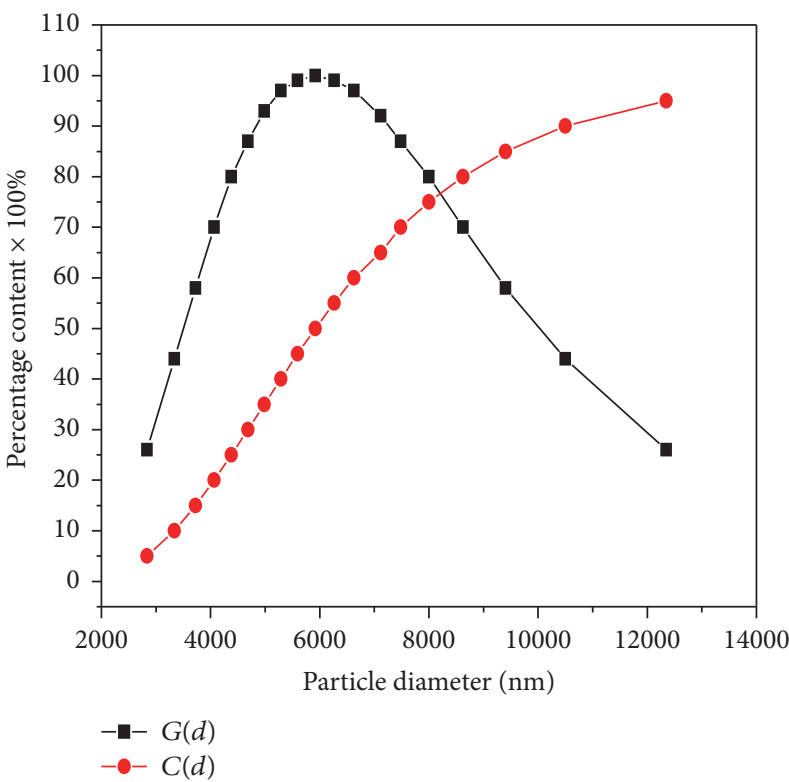

(a) $\mathrm{HMX} / \mathrm{F}_{2602}-0$

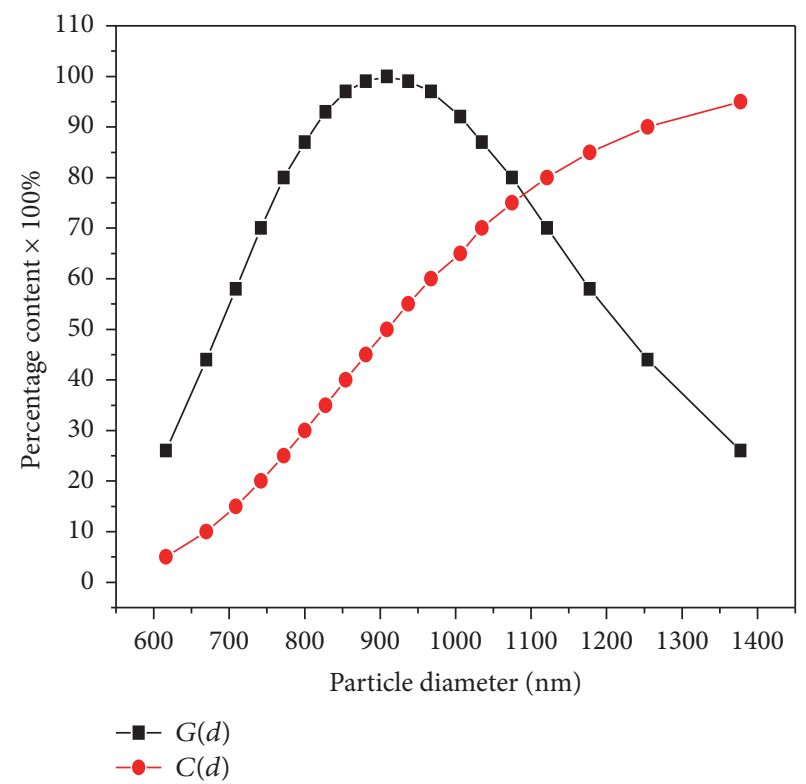

(b) $\mathrm{HMX} / \mathrm{F}_{2602}$

FIGURE 3: Particle size distribution curves of different HMX/F2602 sample.

to investigate the morphology, size, and microstructure of capsules. The prepared HMX/F2602 microspheres were dispersed on conductive carbon adhesive tapes to attach to a FESEM stub and then gold-coated. The crystal form of HMX/F2602 microspheres was detected by X-ray powder diffraction. X-ray diffraction (XRD) ray diffractometer uses the XRD-2700 ray diffractometer. Instrument parameters are as follows: $\mathrm{Cu}$ target $(\mathrm{K} \alpha, \lambda=1.54059 \AA)$, tube voltage for $40 \mathrm{kv}$, electric current for $30 \mathrm{~A}$, the scanning speed for $2^{\circ} / \mathrm{min}$, and the scanning range from $2 \theta=10^{\circ} \sim 50^{\circ}$. The thermal properties were characterized by a Setaran DSC-131 (Setaram, Hillsborough Township, NJ, USA). The conditions of DSC were as follows: sample mass: $0.7 \mathrm{mg}$; heating rate: 5 , $10,20 \mathrm{~K} / \mathrm{min}$; nitrogen atmosphere (flow rate: $20 \mathrm{~mL} / \mathrm{min}$ ). The impact sensitivity test conditions are as follows: drop weight, $5 \mathrm{~kg}$; sample mass, $35 \mathrm{mg}$. The impact sensitivity of each test sample was characterized by the drop height of $50 \%$ explosion probability $\left(H_{50}\right)$. In this way, higher $H_{50}$ value represents reduced impact sensitivity. The average particle size and characterization of distribution were determined by using Hydro2000Mu Melvin Laser Particle Size Analyzer (British Melvin Instrument Co., Ltd.). The work condition is using distilled water as dispersion medium.

\section{Results and Discussion}

3.1. SEM Analysis. The morphologies of the resulting samples were measured by SEM, as depicted in Figure 3. It can be seen from Figure 2(b) that the water suspension process can make $\mathrm{F}_{2602}$ be successfully coated on the surface of HMX, but the 


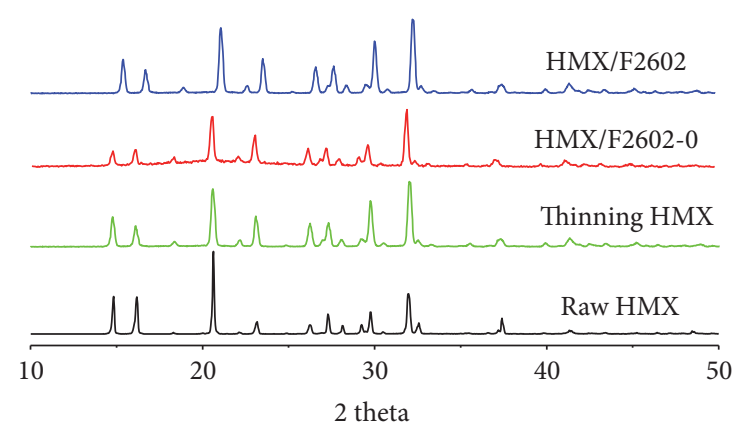

FIgURE 4: X-ray diffraction patterns of different HMX samples.

size of $\mathrm{HMX} / \mathrm{F}_{2602}$ particles is bigger and the morphology is irregular. There exist large coating defects. It can be seen from Figure 3(a) that the median diameter is $5.84 \mu \mathrm{m}$, while, from Figure 2(b), particles obtained by using onestep granulation process have smaller particle size, smooth surface, and dense coating layer. HMX particles are ellipsoidal or spherical and the crystal form tends to be complete. And from Figure 3(b), we can see that the median particle size is $940 \mathrm{~nm}$. The reasons are as follows: on one hand, according to the bonding mechanism [14] and in the process of HMX recrystallization refinement, before entering the nonsolvent, HMX molecules have a greater degree of collision with high-speed moving water vapor molecules. After being sprayed into the nonsolvent, they finishe the second collision with high-speed rotating nonsolvent solution. This kind of collision effectively destroys the attraction among particles, making the thinning HMX particles have smaller size and the crystal morphology tend to be complete. On the other hand, according to diffusion theory [15], spraying the binder through the self-made nozzle makes the diffusion between molecules more obvious and more intense. Under the action of external force, the fog binder rapidly contacts with HMX particles, which avoids the reunion of the particles in a short time, so the coating effect is better.

3.2. XRD Analysis. To investigate whether the phase transformation of HMX occurred, XRD analysis was carried out. X-ray diffraction of raw HMX, thinning HMX, and the $\mathrm{HMX} / \mathrm{F}_{2602}$ particles by water suspension process and onestep granulation process are displayed in Figure 4.

From Figure 4, it can be seen that the morphology of raw material HMX is $\beta$-HMX, and the diffraction peaks of the thinning HMX and the prepared HMX-based PBX can correspond to the diffraction peak position of the raw HMX. This indicates that, during the coating process, the crystal form of HMX does not change, and the intensity of diffraction peak of coated particles is weakened. Reasons for this are that, on one hand, "isotropic" physical properties of amorphous $\mathrm{F}_{2602}$ make the PBX particles be distributed in random in the spatial distribution. The periodic arrangements weaken the intensity of the diffraction of HMX. On the other hand, by changing the energy effect of the solid-liquid interface as well as the dynamic factors in the process to improve the stability of the mechanical properties of the entire coating system,
TABLE 1: Thermal decomposition kinetic parameters of different HMX samples.

\begin{tabular}{lcccc}
\hline Sample description & $E_{a} / \mathrm{kJ} \cdot \mathrm{mol}^{-1}$ & $\log \left(A / s^{-1}\right)$ & $T_{P 0}$ & $T_{b}$ \\
\hline Raw HMX & 359.75 & 33.96 & 274.07 & 275.83 \\
HMX $/ F_{2602}-0$ & 365.23 & 34.31 & 274.05 & 276.18 \\
HMX $/ F_{2602}$ & 419.34 & 39.46 & 276.51 & 278.04 \\
\hline
\end{tabular}

the explosive crystal surface forms a continuous uniform polymer binder coating under the intermolecular van der Waals force. In the $90^{\circ} \mathrm{C}$ high-temperature water vapor environment and under the action of the vacuum pump, the organic solvent for dissolving the binder is removed. This makes the mist binder precipitate and have a good contact with wet explosive particles; thus, polymer particles with smooth surface and smaller size are obtained. This process is a physical one, so the crystal structure has not changed.

3.3. Thermal Analysis. Probing the kinetic and thermodynamic parameters is very important in mastering the thermolysis properties of energetic materials. By DSC, we analyzed thermal performance of thinning HMX and the $\mathrm{HMX} / \mathrm{F}_{2602}$ particles by water suspension coating process and one-step granulation process, calculated their activation energy, and made analysis of thermal performance changes before and after refinement. DSC curve is shown in Figure 5.

According to the three exothermic peaks of particles, the apparent activation energy, the frequency factor, and the peak temperature when $\beta_{i}$ is zero were determined by Kissinger's method $[16,17]$. Furthermore, the thermal stability of explosives can be counted by (2) and (3) [18-20], and the results are shown in Table 1.

$$
\begin{aligned}
\ln \left(\frac{\beta_{i}}{T_{p i}^{2}}\right) & =\ln \left(\frac{A R}{E_{a}}\right)-\frac{E_{a}}{R T_{p i}}, \\
T_{p i} & =T_{p 0}+b \beta_{i}+c \beta_{i}^{2} \\
T_{b} & =\frac{E-\sqrt{E^{2}-4 R E T_{p 0}}}{2 R},
\end{aligned}
$$

where $E_{a}$ is the apparent activation energy; $A$ is the frequency factor; $T$ is the absolute temperature; $\beta_{i}$ is the peak temperature; $\mathrm{K}$ is the decomposition rate constant at $T ; T_{p 0}$ is the peak temperature when $\beta_{i}$ is zero $(\mathrm{K}) ; b$ and $c$ are constants; and $T_{b}$ is the critical explosion temperature $(\mathrm{K})$.

As can be seen from Table 1, the critical temperature of thermal explosion $T_{b}$ of raw HMX, HMX/ $/ \mathrm{F}_{2602}-0$, and $\mathrm{HMX} / \mathrm{F}_{2602}$ are $275.83^{\circ} \mathrm{C}, 276.18^{\circ} \mathrm{C}$, and $278.04^{\circ} \mathrm{C}$, respectively. In addition, compared with raw HMX, their $E_{a}$ increases by 5.89 and $68.59 \mathrm{~kJ} \cdot \mathrm{mol}^{-1}$, respectively. It indicates that the thermal stability of $\mathrm{HMX} / \mathrm{F}_{2602}$ particles by onestep granulation process is superior to not only that of raw material HMX but also that of $\mathrm{HMX} / \mathrm{F}_{2602}-0$ particles by water suspension process. It can be explained that the thermal decomposition characteristics of explosives are related to the particle size [21]. Due to the size effect and surface effect of 


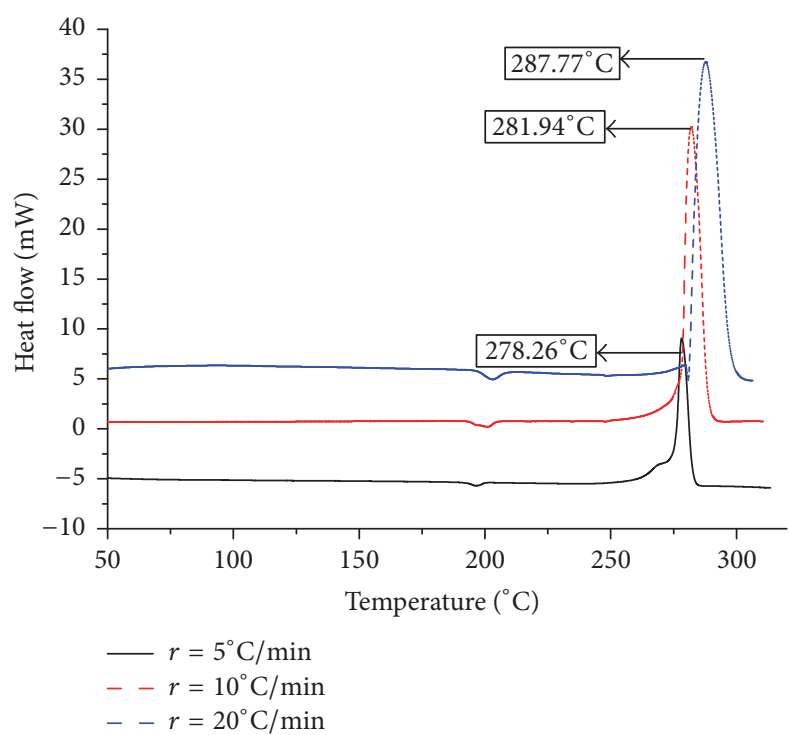

(a)

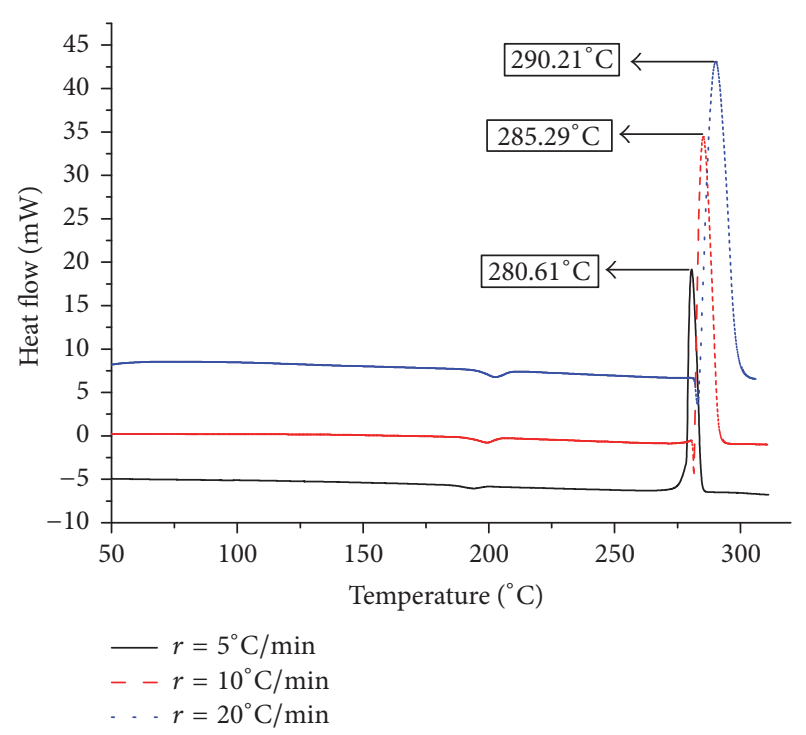

(b)

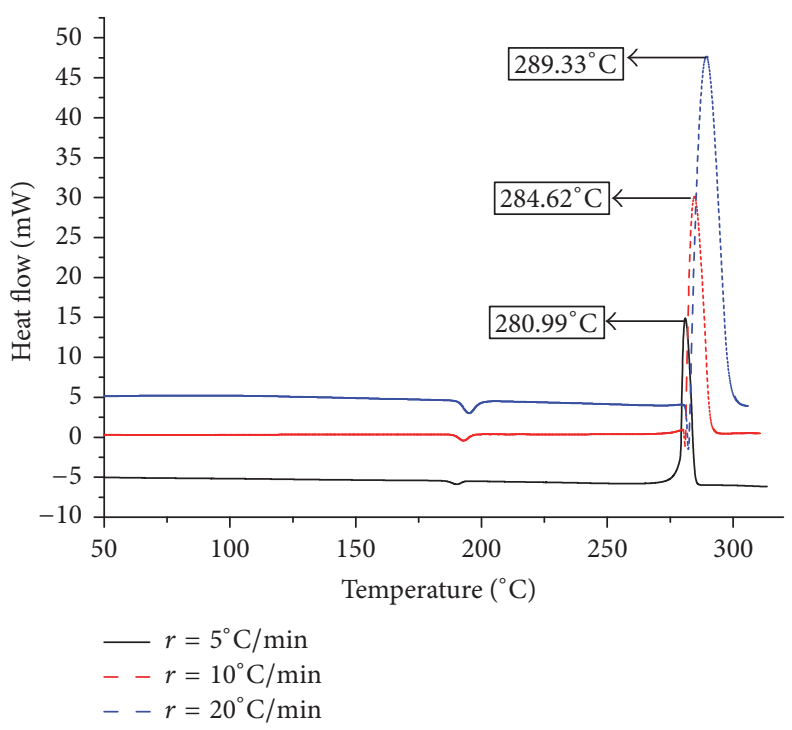

(c)

Figure 5: DSC curves of refined HMX (a), $\mathrm{HMX} / \mathrm{F}_{2602}-0$ (b), and HMX/F $\mathrm{F}_{2602}$ (c).

the $\mathrm{HMX} / \mathrm{F}_{2602}$ particles, the heat release rate for $\mathrm{HMX} / \mathrm{F}_{2602}$ increases; thus, the critical explosion temperature decreases.

3.4. The Impact Sensitivity. Impact sensitivity is also a key parameter to evaluate the safety performance of energetic materials. To investigate the safety performance of the samples, the test of the impact sensitivity was performed. And the test results are shown in Table 2:

As can be seen from Table 2, compared with raw material $\mathrm{HMX}$, the special height $\left(\mathrm{H}_{50}\right)$ of $\mathrm{HMX} / \mathrm{F}_{2602}-0$ by water suspension and that of $\mathrm{HMX} / \mathrm{F}_{2602}$ by one-step granulation process increases by $17.5 \mathrm{~cm}$ and $20.01 \mathrm{~cm}$, respectively, and the impact sensitivity significantly decreases and the safety performance has greatly improved. This can be explained by hot spot theory $[22,23]$ : on one hand, $\mathrm{F}_{2602}$ was successfully
TABLE 2: Impact sensitivity of raw HMX, thinning HMX, HMX/ $\mathrm{F}_{2602}-0, \mathrm{HMX} / \mathrm{F}_{2602}$.

\begin{tabular}{lcc}
\hline Samples & $H_{50} / \mathrm{cm}$ & Standard \\
\hline Raw HMX & 20.12 & 0.237 \\
Thinning HMX & 33.24 & 0.512 \\
HMX/F $2602-0$ & 37.62 & 0.392 \\
HMX $/ F_{2602}$ & 40.13 & 0.443 \\
\hline
\end{tabular}

coated on the surface of HMX, and certain buffer action was produced when using drop hammer to impact, which effectively slows down the formation of hot spot; on the other hand, uniform particle size distribution makes the gap among particles increases, so the stressed area of HMX particles 
with the same quality increases, reducing the stress concentration phenomenon among particles, which effectively prevents the generation of the local hot spots. So $H_{50}$ of $\mathrm{HMX} / \mathrm{F}_{2602}$ particles by one-step granulation process adds more.

\section{Conclusion}

The findings in this way provide a simple and convenient method for preparation of energetic $\mathrm{HMX} / \mathrm{F}_{2602}$ solid microspheres with regular spherical morphology, good thermal stability, and insensitive property. Compared with raw HMX and $\mathrm{HMX} / \mathrm{F}_{2602}-0$ prepared by water suspension, the $\mathrm{HMX} / \mathrm{F}_{2602}$ prepared by one-step granulation process has a unique coreshell structure and narrow particle size distribution of $0.4 \sim$ $1.2 \mu \mathrm{m}$. In the process of preparing $\mathrm{HMX} / \mathrm{F}_{2602}$, the HMX maintains the $\beta$-form, and this means that the one-step granulation process is an effective method to keep the original crystal form of energetic materials. Known from the analysis of DSC, the HMX/F $/ \mathrm{F}_{2602}$ prepared by one-step granulation process has better thermal stability than other samples. In addition, the mechanical sensitivity of $\mathrm{HMX} / \mathrm{F}_{2602}\left(H_{50}\right.$ $=40.13 \mathrm{~cm}$ ) is lower than that of other samples. More importantly, one-step granulation process saves the freezedrying process after recrystallization and the work efficiency increases by 2 to 3 times.

\section{Conflicts of Interest}

The authors declare that they have no conflicts of interest.

\section{Acknowledgments}

This work was supported by the Major Research and Development Project in Shanxi province (no. 201603D121012) and 13th Graduate Students of Science and Technology in North University of China (no. 20161325).

\section{References}

[1] X. Tan, X. Duan, H. Li, and C. Pei, "Method for surface coating of octahdro-1,3,5,7-tetranitro-1,3,5,7-tetrazocine with submicron 1,3,5-triamino-2,4,6-trinitrobenzene," Micro \& Nano Letters, vol. 11, no. 1, pp. 24-28, 2016.

[2] N. Kubota, "Physicochemical processes of HMX propellant combustion," Symposium (International) on Combustion, vol. 19, no. 1, pp. 777-785, 1982.

[3] Ø. H. Johansen, J. D. Kristiansen, R. Gjersøe et al., "RDX and HMX with reduced sensitivity towards shock initiation-RSRDX and RS-HMX," Propellants, Explosives, Pyrotechnics, vol. 33, no. 1, pp. 20-24, 2008.

[4] J. Xiao, Y. Huang, Y. Hu, and H. Xiao, "Molecular dynamics simulation of mechanical properties of TATB/fluorine-polymer PBXs along different surfaces," SCIENCE CHINA Chemistry, vol. 48, no. 6, pp. 504-510, 2005.

[5] X.-F. Ma, J.-J. Xiao, H. Huang, X.-H. Ju, J.-S. Li, and H.-M. Xiao, "Simulative calculation of mechanical property, binding energy and detonation property of TATB/fuorine-polymer PBX," Chinese Journal of Chemistry, vol. 24, no. 4, pp. 473-477, 2006.
[6] X.-J. Xu, H.-M. Xiao, J.-J. Xiao, W. Zhu, H. Huang, and J.-S. Li, "Molecular dynamics simulations for pure $\varepsilon$-CL-20 and $\varepsilon$-CL20-based PBXs," The Journal of Physical Chemistry B, vol. 110, no. 14, pp. 7203-7207, 2006.

[7] J. Chen, J. Wang, and B. Wang, "Study on Preparation Process of e-HNIW Booster Explosive by Water Slurry Method," Chinese Journal of Explosives \& Propellants, vol. 2, article 009, 2009.

[8] X. Guo, G. Ouyang, J. Liu et al., "Massive preparation of reduced-sensitivity nano CL-20 and its Characterization," Journal of Energetic Materials, vol. 33, no. 1, pp. 24-33, 2014.

[9] W. Ji, X. Li, J. Wang, B. Ye, and C. Wang, "Preparation and Characterization of the Solid Spherical HMX/F2602 by the Suspension Spray-Drying Method," Journal of Energetic Materials, vol. 34, no. 4, pp. 357-367, 2016.

[10] K. F. Warner, V. J. Bellitto, D. N. Sorensen, and D. L. Remmers, "Synthesis of Insensitive N-2,4-dinitrophenyl-N1-nitroguanidine," Journal of Energetic Materials, vol. 34, no. 4, pp. 395398, 2016.

[11] Z. Yang, L. Ding, P. Wu, Y. Liu, F. Nie, and F. Huang, "Fabrication of RDX, HMX and CL-20 based microcapsules via in situ polymerization of melamine-formaldehyde resins with reduced sensitivity," Chemical Engineering Journal, vol. 268, pp. 60-66, 2015.

[12] A. K. Nandi, M. Ghosh, V. B. Sutar, and R. K. Pandey, "Surface coating of cyclotetramethylenetetranitramine (HMX) crystals with the insensitive high explosive 1,3,5-triamino-2,4,6trinitrobenzene (TATB)," Central European Journal of Energetic Materials, vol. 9, no. 2, pp. 119-130, 2012.

[13] Z. Na and W.-Z. Xu, "Study on HMX Coated with Polyacrylic Ester," Initiators \& Pyrotechnics, vol. 6, pp. 40-43, 2015.

[14] H. Assadi, F. Gärtner, T. Stoltenhoff, and H. Kreye, "Bonding mechanism in cold gas spraying," Acta Materialia, vol. 51, no. 15, pp. 4379-4394, 2003.

[15] L. He, J. Lin, and B. Shi, "Fick law and the diffusion's thermodynamics theory," Journal of Anqing Teachers College (Natural Science Edition), vol. 4, article 013, 2006.

[16] H. E. Kissinger, "Reaction kinetics in differential thermal analysis," Analytical Chemistry, vol. 29, no. 11, pp. 1702-1706, 1957.

[17] W. Sha, "Determination of activation energy of phase transformation and recrystallization using a modified Kissinger method," Metallurgical and Materials Transactions A: Physical Metallurgy and Materials Science, vol. 32, no. 11, pp. 2903-2904, 2001.

[18] M. F. Foltz, C. L. Coon, F. Garcia, and A. L. Nichols III, “Thermal stability of the polymorphs of hexanitrohexaazaisowurtzitane, Part I," Propellants, Explosives, Pyrotechnics, vol. 19, no. 1, pp. 1925, 1994.

[19] R. Turcotte, M. Vachon, Q. S. M. Kwok, R. Wang, and D. E. G. Jones, "Thermal study of HNIW (CL-20)," Thermochimica Acta, vol. 433, no. 1-2, pp. 105-115, 2005.

[20] R. T. Yang and M. Steinberg, "Reaction kinetics and differential thermal analysis," The Journal of Physical Chemistry C, vol. 80, no. 9, pp. 965-968, 1976.

[21] W. P. King, S. Saxena, B. A. Nelson, B. L. Weeks, and R. Pitchimani, "Nanoscale thermal analysis of an energetic material," Nano Letters, vol. 6, no. 9, pp. 2145-2149, 2006.

[22] J. E. Field, N. K. Bourne, S. J. Palmer, S. M. Walley, J. Sharma, and B. C. Beard, "Hot-Spot Ignition Mechanisms for Explosives and Propellants [and Discussion]," Philosophical Transactions of the 
Royal Society A: Mathematical, Physical \& Engineering Sciences, vol. 339, no. 1654 , pp. 269-283, 1992.

[23] L. Borne, J. Mory, and F. Schlesser, "Reduced sensitivity RDX (RS-RDX) in pressed formulations: Respective effects of intragranular pores, extra-granular pores and pore sizes," Propellants, Explosives, Pyrotechnics, vol. 33, no. 1, pp. 37-43, 2008. 

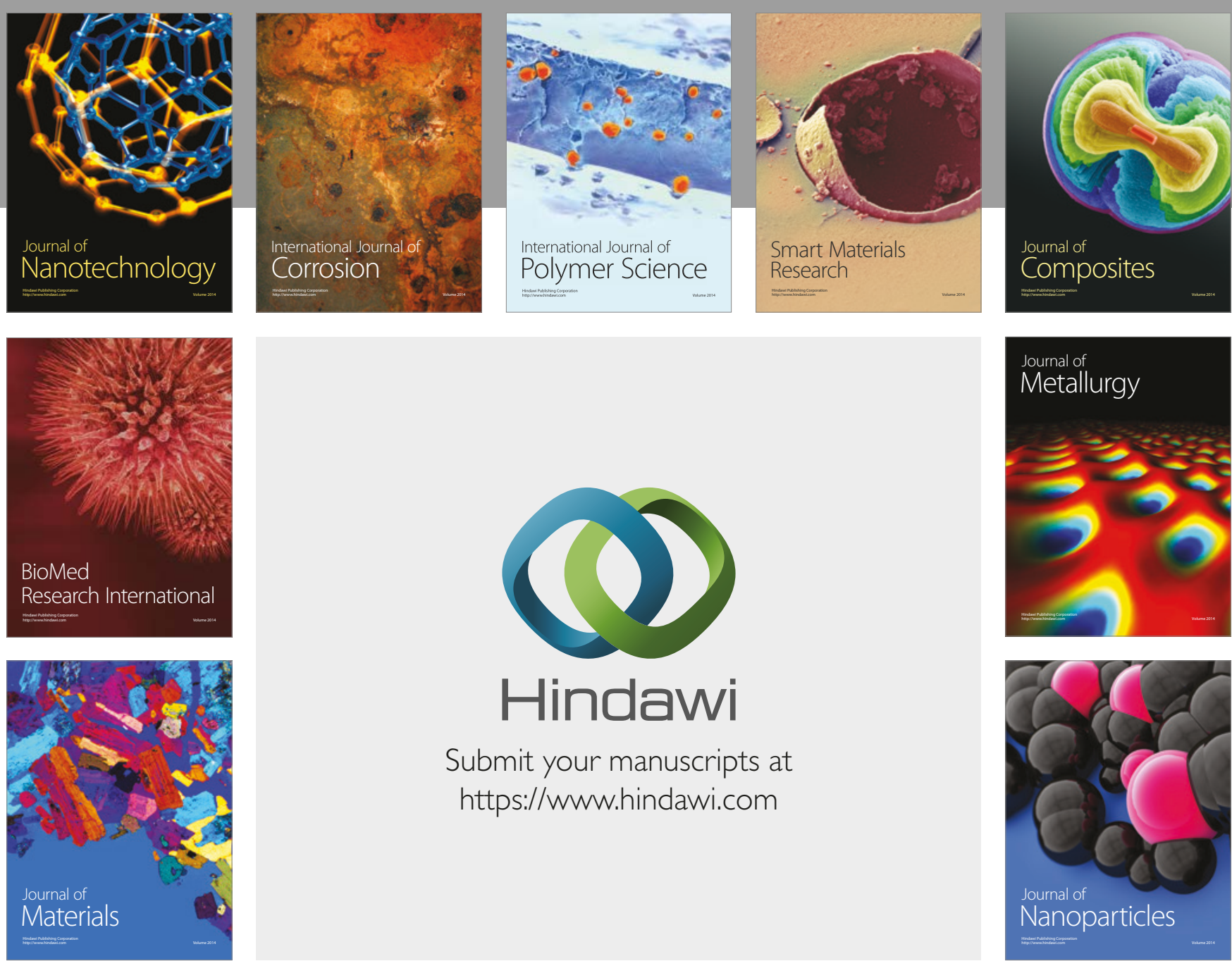

\section{Hindawi}

Submit your manuscripts at

https://www.hindawi.com
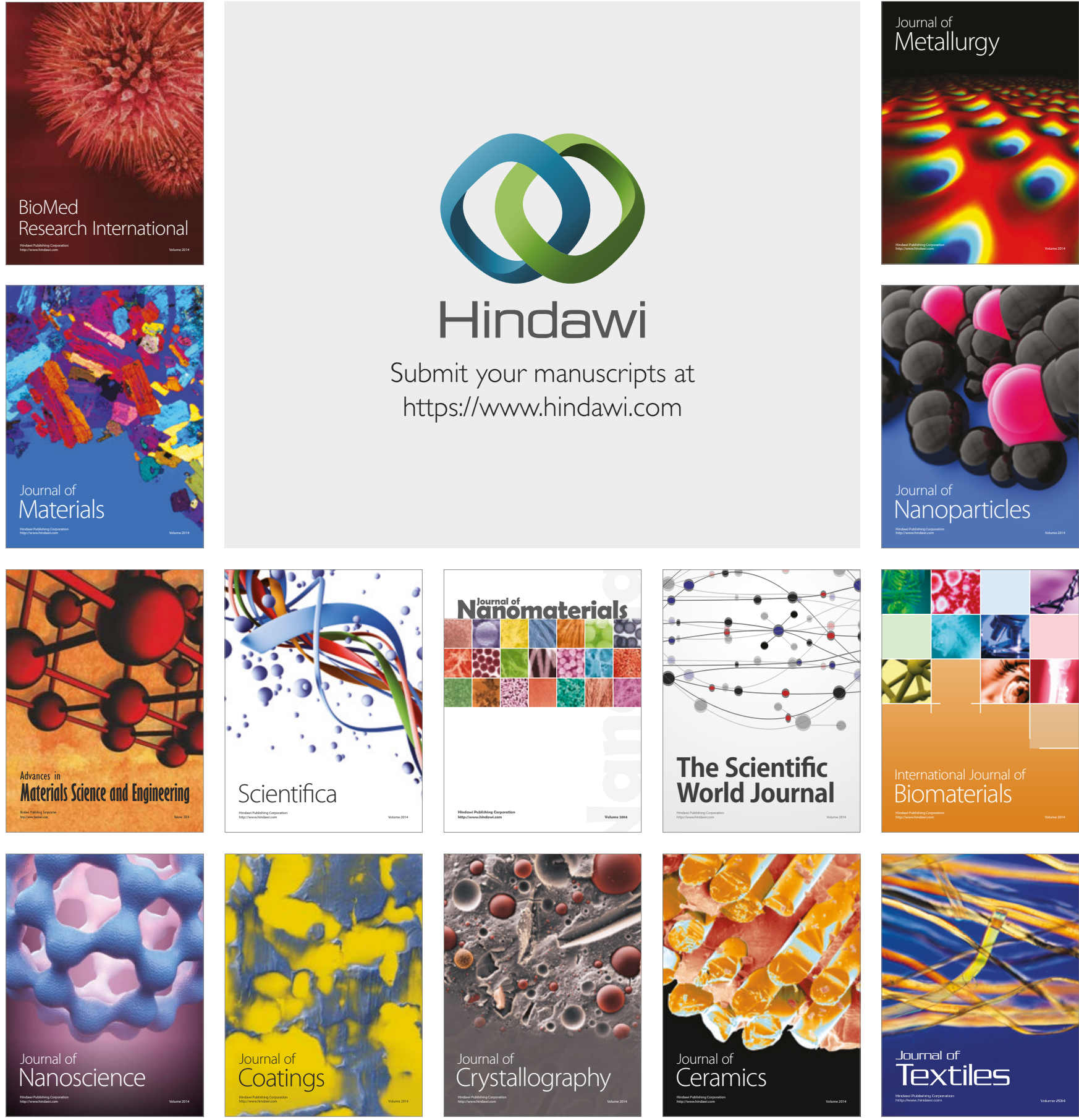

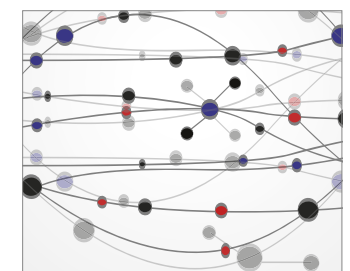

The Scientific World Journal
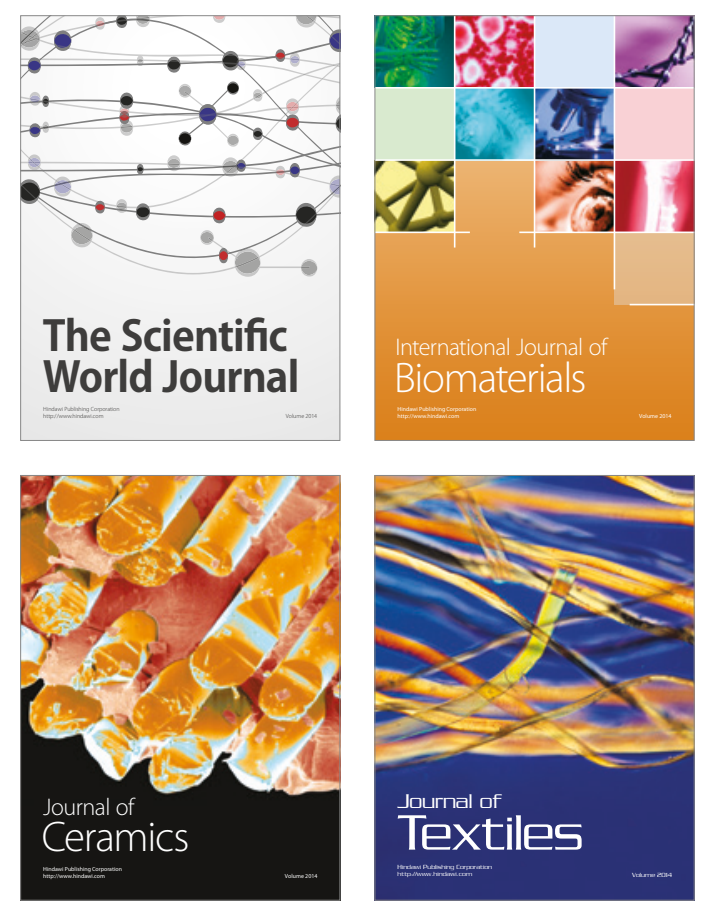